\title{
Efficacy of Methotrexate in Real-world Management of Giant Cell Arteritis: A Case-control Study
}

\author{
Matthew J. Koster, Karthik Yeruva, Cynthia S. Crowson, Francesco Muratore, Cristian Labarca, \\ and Kenneth J. Warrington
}

ABSTRACT. Objective. To determine the effect of methotrexate (MTX) on relapse risk and glucocorticoid (GC) use in a large single-institution cohort of patients with giant cell arteritis (GCA).

Methods. Patients diagnosed with GCA from 1998 to 2013 with confirmed evidence of temporal artery biopsy and/or radiographic evidence of large vessel vasculitis were identified. Each patient with GCA treated with adjunct MTX (case) was matched to a similar patient with GCA treated only with GC (control). GC requirements and relapse events before and after MTX initiation (or corresponding index date) were compared using rate ratios (RR).

Results. Eighty-three cases and 83 controls were identified and compared. No significant differences in age, demographics, laboratory variables, baseline disease characteristics, or mean initial prednisone doses were observed. Median [interquartile range (IQR)] time from GCA diagnosis to MTX initiation in cases was 39 (13-80) weeks and the median (IQR) starting dose was 13.5 (10-15) mg/week. RR comparing relapse rates before and after MTX initiation/index date were significantly reduced in both cases (RR 0.32, 95\% CI 0.24-0.41) and controls (RR 0.60, 95\% CI 0.43-0.86). The decrease in relapse rate was significantly greater in patients taking MTX than in those taking GC alone $(p=0.004)$. Rates of GC discontinuation did not differ between groups.

Conclusion. In this large single-institution cohort, the addition of MTX to GC decreased the rate of subsequent relapse by nearly 2 -fold compared to patients taking GC alone. MTX may be considered as adjunct therapy in patients with GCA to decrease the risk of further relapse events. (First Release January 15 2019; J Rheumatol 2019;46:501-8; doi:10.3899/jrheum.180429)

\section{Key Indexing Terms: GIANT CELL ARTERITIS METHOTREXATE}

VASCULITIS

\section{RELAPSE GLUCOCORTICOIDS}

Giant cell arteritis (GCA) is the most common primary systemic vasculitis among patients aged $\geq 50$ years and has a predilection for affecting the aorta and its primary branches ${ }^{1}$. Because of associated severe ischemic complications including vision loss, stroke and aortic aneurysm/dissection,

From the Mayo Clinic College of Medicine and Science, Department of Internal Medicine, Division of Rheumatology, and the Mayo Clinic College of Medicine, Department of Health Sciences Research, Rochester, Minnesota, USA; Division of Rheumatology, Azienda Ospedaliera, Unità Sanitaria Locale-Institute for Research and Health Care (USL-IRCCS) di Reggio Emilia e Università di Modena e Reggio Emilia, Modena e Reggio Emilia, Italy; Universidad Del Desarrollo, Clinica Alemana, Santiago, Chile.

M.J. Koster, MD, Mayo Clinic College of Medicine and Science, Department of Internal Medicine, Division of Rheumatology; K. Yeruva, MD, Mayo Clinic College of Medicine and Science, Department of Internal Medicine, Division of Rheumatology; C.S. Crowson, PhD, Mayo Clinic College of Medicine and Science, Department of Internal Medicine, Division of Rheumatology, and the Mayo Clinic College of Medicine, Department of Health Sciences Research; F. Muratore, MD, Division of Rheumatology, Azienda Osedaliera, USL-IRCCS di Reggio Emilia e Università di Modena e Reggio Emilia; C. Labarca, MD, Universidad Del Desarrollo, Clinica Alemana; K.J. Warrington, MD, Mayo Clinic College of Medicine and Science, Department of Internal Medicine, Division of Rheumatology.

Address correspondence to Dr. M.J. Koster, Mayo Clinic, 200 1st St. SW, Rochester, Minnesota 55905,USA.E-mail: koster.matthew@mayo.edu Accepted for publication October 10, 2018. prompt diagnosis and initiation of treatment is required ${ }^{2,3}$. High-dose glucocorticoids (GC) followed by a tapering regimen have remained the mainstay for treatment of patients with $\mathrm{GCA}^{4,5}$.

Despite treatment with GC, $40-75 \%$ of patients experience at least 1 relapse during the course of followup ${ }^{6,7}$. Patients experiencing relapses have demonstrated both a longer duration and greater cumulative exposure to $\mathrm{GC}^{8}$. Unfortunately, longterm GC treatment in the age group affected by GCA is associated with a high number of adverse events, which have been reported in $86-100 \%$ of patients ${ }^{8,9}$.

Tocilizumab (TCZ), an interleukin 6 (IL-6) receptor inhibitor, in combination with an accelerated (26-week) GC taper, has recently been shown to be effective in the treatment of both newly diagnosed and relapsing patients with $\mathrm{GCA}^{10}$. However, the substantial cost of this targeted biologic may preclude its use in some patients with GCA. Methotrexate (MTX) is a less expensive option for treatment, but clinical trial use of this agent in newly diagnosed patients with active disease has provided conflicting results ${ }^{11,12,13}$. A metaanalysis of individual patient data from these studies demonstrated a modest reduction in cumulative GC use and moderate absolute reduction in relapse risk; however, a reduction in GC-associated adverse events was not

Personal non-commercial use only. The Journal of Rheumatology Copyright @ 2019 . All rights reserved. 
observed ${ }^{14}$. Findings from the metaanalysis have also suggested that the disparate results from the individual clinical trials may be in part due to inadequate sample sizes, as well as differences in trial design regarding dose of MTX chosen, method of steroid tapering, choice of outcome measures, number of relapses allowed and length of followup ${ }^{14}$.

Clinical trials evaluating MTX among patients with established relapsing disease have not been performed to date, and cohort studies describing the efficacy of MTX in GCA are limited ${ }^{15,16}$. The purpose of this study was to describe the use of MTX in a large cohort of patients with relapsing GCA and compare them to patients with GCA receiving only GC therapy from the same institution.

\section{MATERIALS AND METHODS}

A retrospective chart review was performed identifying all patients diagnosed with GCA from 1998 to 2013, combining 2 previously defined cohorts $^{7,17}$. Patients diagnosed with GCA were $\geq 50$ years of age, had clinical symptoms consistent with GCA and had either a positive temporal artery biopsy and/or radiographic evidence of large-vessel vasculitis. Findings considered compatible with large-vessel vasculitis included the presence of one or more of the following: circumferential wall thickening and/or the presence of vascular stenosis/occlusion and/or vascular dilatation/aneurysm not attributed to atherosclerotic changes on computed tomography angiogram; presence of circumferential wall thickening/wall edema with or without contrast enhancement and/or the presence of vascular stenosis/occlusion and/or vascular dilatation/aneurysm not attributed to atherosclerosis on magnetic resonance angiogram; arterial hypermetabolism demonstrated by fluorodeoxyglucose uptake compatible with vasculitis on 18F-fluorodeoxyglucose positron emission tomography (FDG-PET). Ultrasonography was not used in our study to evaluate for large-vessel involvement.

All patients treated with adjunct MTX during the course of their disease were identified. Each patient with GCA treated with adjunct MTX (case) was matched to a similar patient with GCA treated with only GC (control). Cases and controls were matched on age, sex, disease duration, and initial $\mathrm{GC}$ dose. Each control was assigned an index date to make the number of days from GCA diagnosis to index date in the control equivalent to the number of days from GCA diagnosis to the start of MTX in cases.

Baseline demographics, disease characteristics, and relapse events were abstracted. Relapse was defined as the reappearance of symptoms of GCA and/or polymyalgia rheumatica associated with an increase in erythrocyte sedimentation rate and/or C-reactive protein for which treatment was escalated. Timing of initiation, initial dose, and titration/taper of MTX and GC were not standardized and were at the discretion of the treating provider. Use and adherence to prescribed MTX dosing regimens were evaluated through the prescribing physician's routine documentation of patient-reported compliance at the time of each physician visit. Dose reduction of MTX was defined as a decrease in MTX $\geq 25 \%$ of the current dose for $\geq 3$ months. Discontinuation was defined as permanent cessation of treatment without subsequent reintroduction. Transient interruptions $(\leq 6$ weeks) for minor infection, surgical procedure, or failure to obtain medication from pharmacy were not considered as either MTX dose reduction or discontinuation. Lack of efficacy and sustained clinical response was determined by the treating rheumatologist.

Descriptive statistics (means, medians, percentages, etc.) were used to summarize the data. Comparisons between groups were performed using chi-square and rank-sum tests. Relapse rates were defined as the total number of relapses (including multiple relapses per patient) divided by the total number of person-years of followup in each group. GC requirements and relapse events before and after MTX initiation (or corresponding index date) were compared using rate ratios (RR). RR for relapses were calculated individually for cases and controls, comparing the rate of relapses before and after MTX initiation (cases) or corresponding index date (controls). In addition, the reduction in the relapse rates between cases and controls was compared to estimate the treatment effect. CI of 95\% were computed for RR assuming that the observed number of relapses in each group followed a Poisson distribution. Adjustment for initial GC dose at GCA diagnosis and time-dependent covariates for $\mathrm{GC}$ use during followup was performed using conditional frailty models, which are a variation of Cox models that account for multiple relapses in the same patient using a random subject effect. Analyses were performed using SAS version 9.4 (SAS Institute) and R 3.2.3 (R Foundation for Statistical Computing).

This study was approved by the Institutional Review Board (IRB) of the Mayo Clinic, Rochester, Minnesota, USA (IRB\# 14-001179).

\section{RESULTS}

A total of 83 patients with GCA receiving MTX (cases) were identified and compared to 83 patients with GCA receiving GC only (controls). Mean ( \pm SD) age at diagnosis was 69.4 \pm 7.0 years in cases and 70.2 \pm 7.1 years in controls. Median [interquartile range (IQR)] followup for cases was 4.0 (2.3-6.0) years and 3.9 (2.3-7.7) years for controls $(\mathrm{p}=0.43)$. No significant differences in demographics, laboratory variables, or baseline disease characteristics were observed between groups (Table 1).

Mean initial prednisone doses at GCA diagnosis were similar $(53.7 \pm 14.7 \mathrm{mg} /$ day in cases, $54.3 \pm 13.7 \mathrm{mg} /$ day in controls). The median (IQR) time from GCA diagnosis to MTX initiation in cases was 39 (13-80) weeks and the median (IQR) starting dose of MTX was 13.5 (10-15) mg per week. Median maximum MTX dose (mg/week) was 15.0 (12.5-20.0). Prior to MTX initiation, 24 patients (29\%) had not yet experienced a relapse, whereas 23 patients $(28 \%)$ had 1 relapse, $19(23 \%)$ had 2 relapses, and $17(20 \%)$ had 3 or more relapses. In comparison, at index date among patients receiving only GC (controls), 59 (71\%) had not yet experienced a relapse, $9(11 \%)$ had 1 relapse, $10(12 \%)$ had 2 relapses, and $5(6 \%)$ had 3 or more relapses.

The observed relapse rate prior to MTX initiation (cases) was 11.8 relapses per 10 person-years and decreased to 3.72 relapses per 10 person-years following introduction of MTX. The RR comparing relapse rates observed after MTX to the rate prior to initiation was significantly reduced (RR 0.32 , 95\% CI 0.24-0.41). Adjusting for GC starting dose and GC use during followup, the RR for comparing the relapse rates before and after MTX initiation in the MTX arm was slightly attenuated, with an HR of 0.36 (95\% CI 0.27-0.48), but it remained significant. In the control group the relapse rate was 4.45 relapses per 10 person-years before the index date and 2.68 relapses per 10 person-years following the index date (RR $0.60,95 \%$ CI $0.43-0.86$ ). Although both groups had a reduction in relapse rate, the decrease in relapse rate was significantly greater in patients taking MTX (cases) than those taking GC alone (controls; $\mathrm{p}=0.004$; Figure 1).

A subset analysis of only relapsing patients was additionally performed. Owing to the higher frequency of

Personal non-commercial use only. The Journal of Rheumatology Copyright @ 2019. All rights reserved. 
Table 1. Characteristics of patients with GCA treated with GC plus adjunct MTX compared to GC alone.

\begin{tabular}{lccc}
\hline Characteristic (\%) & MTX $+\mathrm{GC}, \mathrm{n}=83$ & $\mathrm{GC}$ alone, $\mathrm{n}=83$ & $\mathrm{p}$ \\
\hline Age at diagnosis, yrs* & $69.4 \pm 7.0$ & $70.2 \pm 7.1$ & 0.41 \\
Female sex & $70(84)$ & $70(84)$ & 1.00 \\
Smoking, ever & $33(40)$ & $28 / 80(35)$ & 0.36 \\
Diabetes mellitus & $7(8)$ & $5(6)$ & 0.55 \\
Hypertension & $39 / 80(49)$ & $41(49)$ & 0.93 \\
Dyslipidemia & $33 / 82(40)$ & $39 / 82(48)$ & 0.35 \\
Length of followup, yrs ${ }^{\gamma}$ & $4.0(2.3-6.0)$ & $3.9(2.3-7.7)$ & 0.43 \\
Time from GCA diagnosis to MTX start/index, weeks ${ }^{\gamma}$ & $39(13-80)$ & $39(13-80)$ & 1.00 \\
Initial MTX dose, mg/week ${ }^{\gamma}$ & $13.5(10.0-15.0)$ & - & - \\
Initial prednisone dose, mg/day* & $53.7 \pm 14.7$ & $54.3 \pm 13.7$ & 0.87 \\
Positive temporal artery biopsy & $58(70)$ & $60(72)$ & 0.73 \\
Headache & $42(51)$ & $50(60)$ & 0.21 \\
Jaw claudication & $31(37)$ & $34(41)$ & 0.63 \\
Temporal artery tenderness & $24(29)$ & $19(23)$ & 0.40 \\
Vision loss, transient & $11(13)$ & $9(11)$ & 0.63 \\
Vision loss, permanent & $4(5)$ & $6(7)$ & 0.51 \\
Polymyalgia rheumatica & $30(36)$ & $23(28)$ & 0.24 \\
Arm claudication & $27(33)$ & $19(23)$ & 0.17 \\
Leg claudication & $7(8)$ & $5(6)$ & 0.56 \\
ESR, mm/h* & $76.4 \pm 37.1$ & $66.5 \pm 33.3$ & 0.17 \\
CRP, mg/l* & $61.3 \pm 47.4$ & $72.4 \pm 75.1$ & 0.96 \\
Creatinine, mg/dl* & $0.9 \pm 0.3$ & $0.9(0.2)$ & 0.43 \\
Albumin, g/d1* & $3.4 \pm 0.6$ & $3.3(0.5)$ & 0.46 \\
AST, U/1* & $25.9 \pm 15.0$ & $25.9(22.0)$ & 0.22 \\
& & & \\
& & &
\end{tabular}

Data are $\mathrm{n}(\%)$ unless otherwise indicated. $*$ Mean $\pm \mathrm{SD} .{ }^{\gamma}$ median (interquartile range). GCA: giant cell arteritis; GC: glucocorticoid; MTX: methotrexate; AST: aspartate aminotransferase; ESR: erythrocyte sedimentation rate; CRP: C-reactive protein.

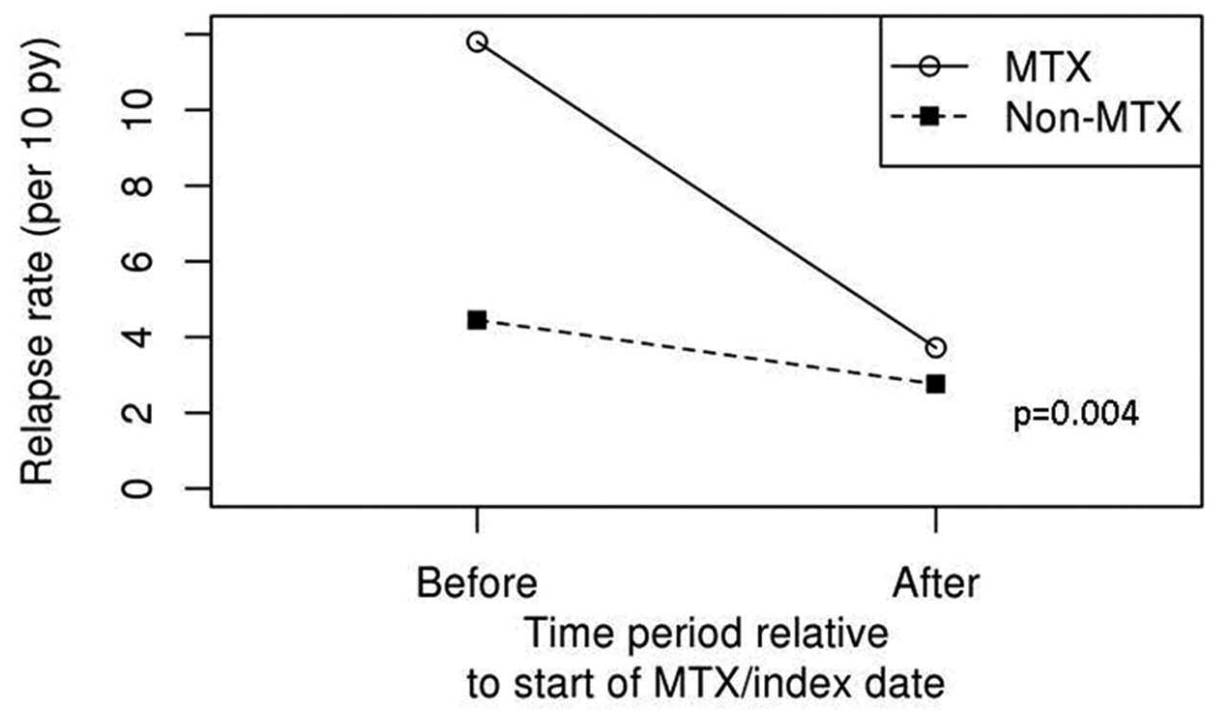

Figure 1. The relapse rate of patients taking methotrexate (MTX) decreased from 11.8 relapses per 10 person-years to 3.72 relapses per 10 person-years following introduction of MTX. In those not taking MTX, the relapse rate was 4.45 relapses per 10 person-years before the index date and 2.68 relapses per 10 person-years following the index date. Although both groups had a reduction in relapse rate, the decrease in relapse rate was significantly greater in patients taking MTX than those not taking MTX $(p=0.004)$. 
relapses in the MTX group, cases and controls could not be individually matched on the number of relapses prior to MTX initiation/index date without significantly reducing the number of matched pairs. Therefore, patients were categorized as relapsers if 1 or more relapses occurred prior to MTX initiation or index date. In total, 59 patients in the MTX group had 1 or more relapses prior to MTX initiation, whereas only 24 patients in the GC-only control group had relapsed prior to index date. The relapse rate in the cases was 12.22 relapses per 10 person-years prior to index date and decreased to 3.21 relapses per 10 person-years after MTX initiation (RR 0.26, 95\% CI 0.19-0.36). For the control group, the relapse rate prior to index date was 7.00 and decreased to 1.65 (RR $0.24,95 \%$ CI 0.13-0.42). The decrease in relapse rates between cases and controls among patients with 1+ relapse prior to MTX initiation/index date was similar $(\mathrm{p}=0.74)$. In comparing the complete case and control cohorts, time to first relapse following MTX initiation/index date did not differ (Figure 2). Among patients treated with MTX that relapsed, $34.5 \pm 5.8 \%$ had experienced at least 1 subsequent relapse at 1 year and $63.7 \pm 8.1 \%$ at 5 years, compared to $35.5 \pm 5.7 \%$ and $77.6 \pm 10.2 \%$ at 1 year and 5 years, respectively, in the GC-only group $(\mathrm{p}=0.65)$.

The median (IQR) cumulative prednisone dose at the time of MTX initiation/index did not differ between groups [cases: $9.5 \mathrm{~g}$ (4.7-14.8); controls $8.1 \mathrm{~g}(3.2-10.8), \mathrm{p}=0.15]$. The mean dose of prednisone at time of MTX initiation in cases was $24.4 \mathrm{mg}( \pm 16.6)$ and $20.5 \mathrm{mg}( \pm 21.0)$ in controls $(\mathrm{p}=0.02)$. The rates of prednisone tapering were similar between cases and controls throughout the study period (Figure 3). The mean annual prednisone dose reduction for cases and controls was also similar throughout followup (Appendix 1). The RR after MTX initiation/index date did not differ between cases and controls for achieving steroid doses of $<10 \mathrm{mg}$ /day for $>6$ months (RR $0.77,95 \% \mathrm{CI}$ $0.52-1.15$ ) or steroid discontinuation for $>6$ months (RR $0.90,95 \%$ CI $0.47-1.64)$. Although the rate of steroid tapering did not differ between groups, because patients in the MTX group started at a higher prednisone dose, the median additional cumulative prednisone dose from MTX start/index date to 1 year and 2 years after start/index was higher in patients receiving MTX [1 yr: $5.0 \mathrm{~g}$ (3.9-8.4); 2 yrs: $8.1 \mathrm{~g}$ (5.4-14.1)] compared to patients receiving GC alone [1 yr: $3.5 \mathrm{~g}(1.7-7.4), \mathrm{p}=0.009 ; 2$ yrs: $5.7 \mathrm{~g}(2.2-9.1), \mathrm{p}=0.01]$.

Information regarding longterm tolerability of MTX was available for 79 of the 83 patients. During the course of followup the MTX dose was decreased by $\geq 25 \%$ in 23 patients; 5 (22\%) of the decreases were due to adverse drug event and $18(78 \%)$ secondary to sustained clinical response. Reported adverse events leading to dose reduction were fatigue $(n=1)$, gastrointestinal intolerance $(n=1)$, dizziness $(\mathrm{n}=1)$, myelosuppression $(\mathrm{n}=1)$, and drug interaction $(n=1)$. At 1 year, 2 years, and 5 years of followup, the percentage of patients ( \pm standard error) with reduction of MTX $\geq 25 \%$ due to adverse event were $4.0 \pm 2.3 \%, 7.4 \pm$ $3.2 \%$, and $7.4 \pm 3.2 \%$, respectively (Figure 4 ). However, the percentage of patients ( \pm standard error) with dose reduction of MTX $\geq 25 \%$ due to sustained clinical response was observed in $4.0 \pm 2.3 \%$ at 1 year, $11.8 \pm 3.9 \%$ at 2 years, and $34.9 \pm 8.3 \%$ at 5 years.

MTX was discontinued during followup in 33 patients. Reasons for discontinuation included adverse drug event (n $=16,48 \%)$, lack of efficacy $(\mathrm{n}=6,18 \%)$, and sustained clinical response $(n=11,33 \%)$. Discontinuation included the following non-mutually exclusive reasons: fatigue $(n=5)$, gastrointestinal intolerance $(n=5)$, alopecia $(n=2)$, dizziness $(\mathrm{n}=2)$, transaminitis $(\mathrm{n}=2)$, myelosuppression $(\mathrm{n}=2)$, cough $(n=1)$, and other $(n=2)$. At 1 year, 2 years, and 5

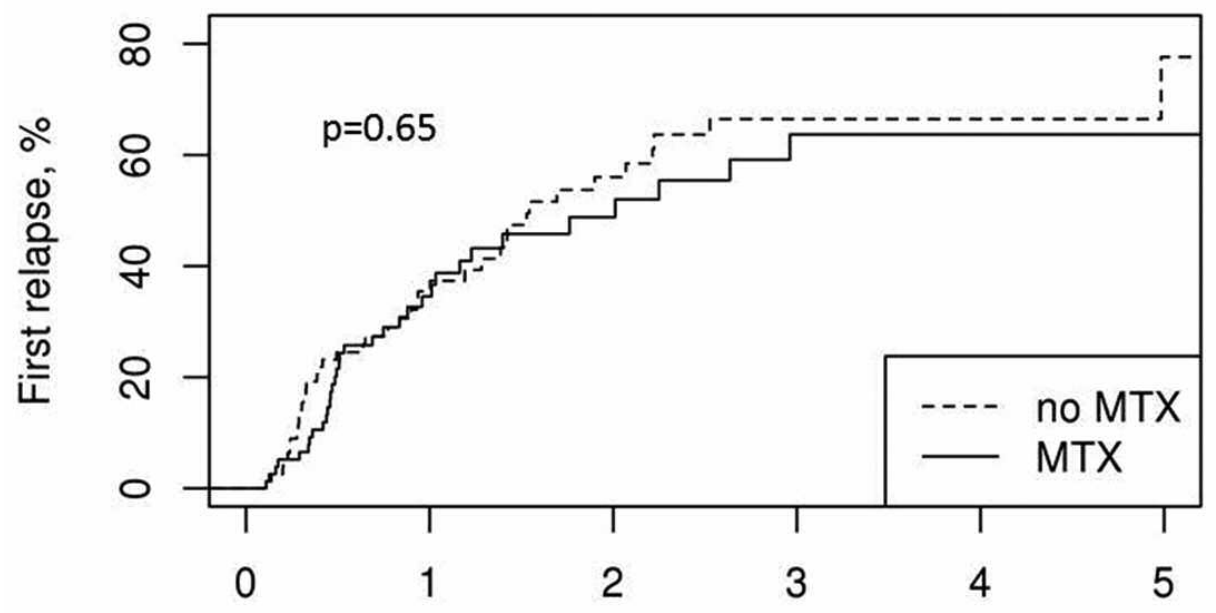

Time since MTX start/index date, years

Figure 2. Time to first relapse after methotrexate (MTX) initiation/index date comparing patients treated with MTX plus glucocorticoids (GC) versus GC alone.

Personal non-commercial use only. The Journal of Rheumatology Copyright @ 2019. All rights reserved 


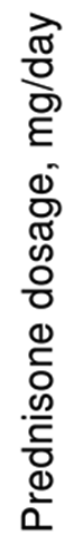

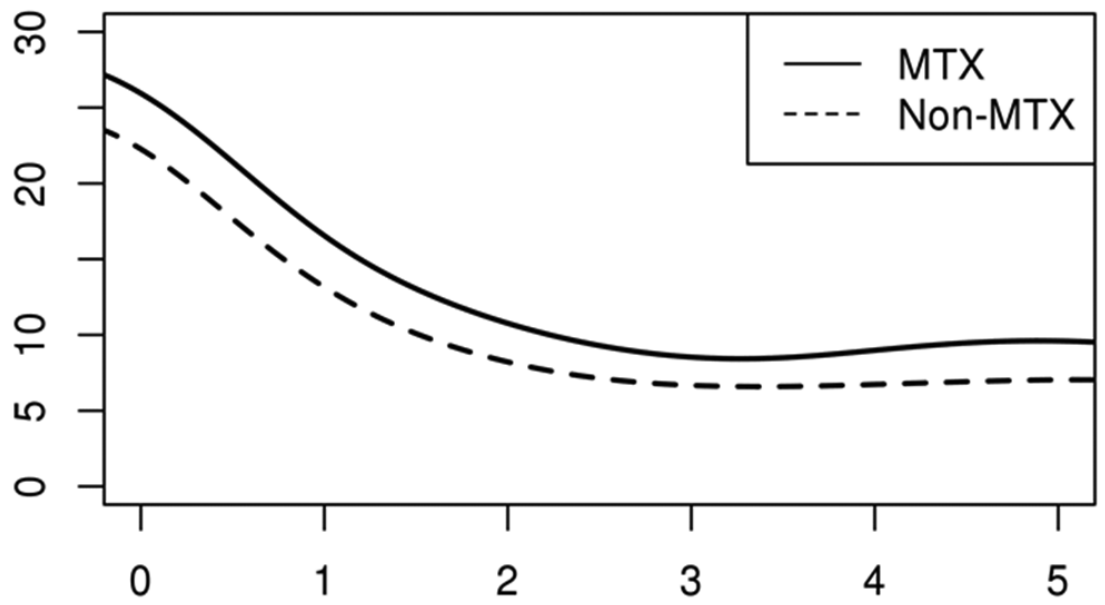

Time since MTX start/index, years

Figure 3. Prednisone tapering during study period. Average prednisone dose (mg/day) from methotrexate (MTX) initiation/index date in cases (solid line) compared to controls (dotted line).

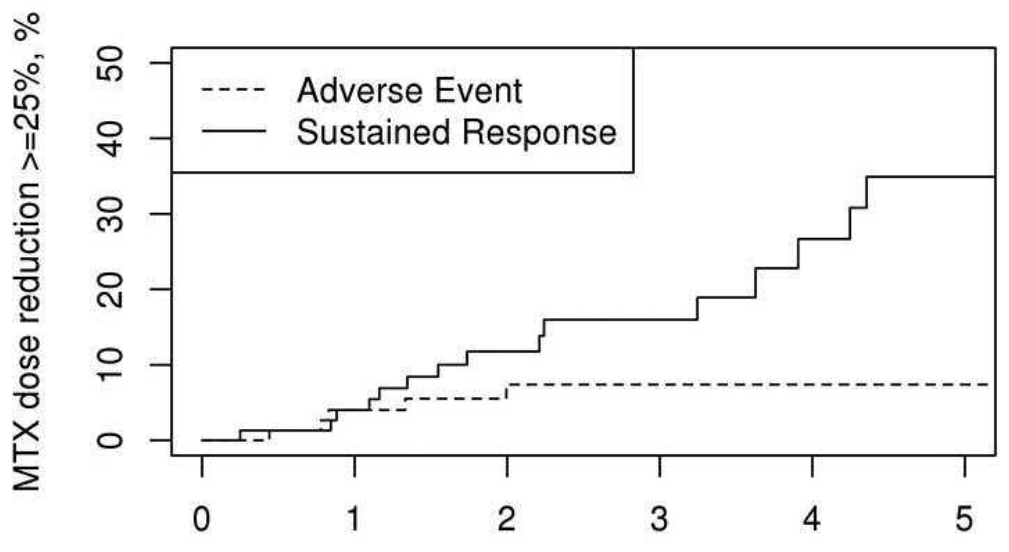

Time since MTX initiation, years

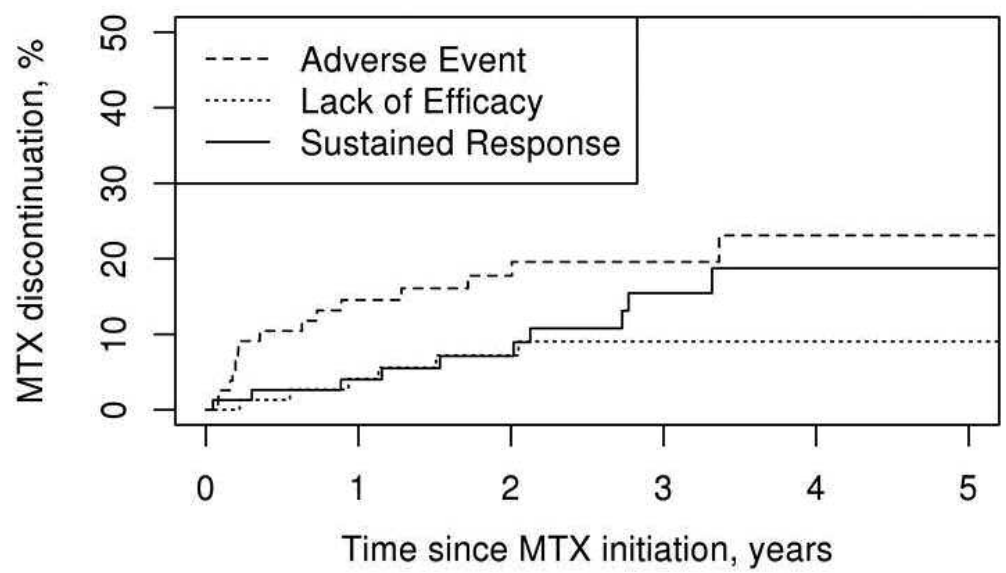

Figure 4. Methotrexate (MTX) tolerability in patients with giant cell arteritis. Upper panel: time from MTX initiation to reduction of MTX by $\geq 25 \%$ because of adverse event (dashed line) or sustained clinical response (solid line). Lower panel: time from MTX initiation to discontinuation because of adverse event (dashed line), lack of efficacy (dotted line), or sustained clinical response (solid line). 
years of followup, the percentages of patients $( \pm$ standard error) with discontinuation of MTX due to adverse event were $14.5 \pm 4.1 \%, 17.7 \pm 4.5 \%$, and $23.1 \pm 5.7 \%$, respectively (Figure 4). The percentages of patients ( \pm standard error) with discontinuation of MTX due to lack of efficacy were $4.1 \pm$ $2.3 \%$ at 1 year, $7.2 \pm 3.1 \%$ at 2 years, and $9.0 \pm 3.6 \%$ at 5 years. The percentages of patients with discontinuation of MTX due to sustained clinical response were $4.0 \pm 2.3 \%$ at 1 year, $7.1 \pm 3.1 \%$ at 2 years, and $18.7 \pm 5.7 \%$ at 5 years

\section{DISCUSSION}

This retrospective report comprises the largest North American, single-institution, case-control study evaluating the real-world efficacy and tolerability of MTX treatment in patients with GCA, to our knowledge. The results of our study demonstrate that patients with GCA treated with MTX have a nearly 2-fold reduction in relapse events after MTX initiation compared to patients treated with GC alone.

Clinical trials evaluating MTX in GCA have focused primarily on newly diagnosed patients ${ }^{11,12,13}$. While these trials demonstrated disparate results, limitations in the studies have included relatively short durations of followup, low MTX doses ( $7.5 \mathrm{mg}$ to $15 \mathrm{mg} /$ week), differing methods of steroid tapering, and small sample sizes. Indeed, among the 3 trials a combined total of only 84 patients received MTX compared to 77 patients receiving placebo. Although only 1 of the 3 trials $^{13}$ reported significant benefit of MTX use, a metaanalysis of individual patient data from the 3 clinical trials did identify evidence that MTX reduced the risk of first relapse by $35 \%$ and second relapse by $51 \%{ }^{14}$.

Based on the observed modest effect of MTX, some experts have recommended that MTX should be considered for use as adjunctive therapy in patients with large-vessel vasculitis ${ }^{4}$. Unfortunately, further guidance on the optimal patient subset, timing of initiation, dose, and duration were not outlined. Other expert consensus guidelines have suggested use of MTX in relapsing patients (3 or more relapses) or in patients who do not taper off $\mathrm{GC}^{5}$. However, investigation of MTX use in this specific subset of patients is limited to 2 small case series ${ }^{18,19}$. Leon and colleagues have recently reported an observational cohort of 168 patients with GCA; $65 \%$ were exposed to treatment with MTX, 50\% of which were started within 1 month of diagnosis ${ }^{16}$. Overall, $31 \%$ of patients had a relapse during followup, and in multivariate analysis patients with GCA exposed to MTX had a $72 \%$ lower risk of relapse compared to those not exposed to $\mathrm{MTX}^{16}$. Unfortunately, information regarding relapse frequency prior to MTX was not included in the analysis.

In our current study, patients with high frequency of relapse benefited from initiation of adjunct MTX, with a 3 -fold reduction in the frequency of relapses per 10 person-years. It is of note, however, that patients treated with only GC also had a reduction in relapse frequency over time. Nevertheless, the reduction in relapse rate in patients taking
GC monotherapy was about $50 \%$ less than that observed in patients receiving MTX. Matching of patients receiving adjunct MTX (cases) to those receiving only GC (controls) was based on age, sex, duration of disease, and initial GC dose. It was not feasible to match based on number of observed relapses prior to MTX initiation/index date because the majority of patients treated with MTX had a substantially higher frequency of relapse compared to controls. A subset analysis evaluating the relapse rate reduction in cases and controls with $1+$ relapses was attempted. This did not demonstrate a significant difference between the relapse rate reduction between cases and controls. However, it is of note that only 24 of the 83 controls had $1+$ relapse and only 5 of 83 had $3+$ relapses compared to 59 and 17 patients in the cases, respectively. Therefore, it is plausible that benefit of MTX in patients with GCA may occur predominantly among patients with increased risk and/or high observed frequency of relapse and MTX may not convey the same benefit to all patients affected by this condition.

Among patients in clinical trials, MTX use provided a higher probability of achieving sustained discontinuation of $\mathrm{GC}$ for $>24$ weeks and also a modest reduction of GC exposure at weeks $48(842 \mathrm{mg})$ and $96(1101 \mathrm{mg})$. However, the onset of action of MTX in patients with GCA appeared to be delayed in conveying benefit because the superiority of MTX over placebo appeared only after 24-36 weeks of continued use ${ }^{14}$. In our current study, the ratio of patients achieving GC doses of $\leq 10 \mathrm{mg} /$ day and GC discontinuation were similar among cases and controls. Although the reasons for such findings are unknown, given no standardized tapering regimen was used and clinicians tapered according to preference, it is possible that more cautious GC reductions were used because of the higher frequency of relapses observed among cases prior to MTX initiation. Other retrospective case series and cohort studies have not included information regarding GC tapering ${ }^{16,18,19}$, so it is unknown whether these findings reflect patient preference, physician bias, disease severity, or a combination thereof.

Overall, longterm use of MTX was tolerated in this patient population despite higher initial and maximum MTX doses compared to other studies ${ }^{11,12,13,20}$. At 5 years of followup, only $23 \%$ of patients had discontinued because of adverse drug event. Similar to the cohort described by Leon, et $a l^{15}$, the current cohort demonstrated that sustained clinical efficacy was the second most frequent cause of treatment discontinuation (18.7\% at $5 \mathrm{yrs}$ ), and termination of MTX treatment for lack of efficacy was uncommon.

The results of the TCZ in GCA (GiACTA) study have demonstrated the superiority of IL-6 inhibition with an accelerated (26-week) GC taper compared to GC alone in the treatment of both newly diagnosed and relapsing patients with $\mathrm{GCA}^{10}$. While the results of this landmark study are significant, it is noteworthy that $23 \%$ of patients receiving weekly and $26 \%$ of patients receiving every other week TCZ

Personal non-commercial use only. The Journal of Rheumatology Copyright @ 2019 . All rights reserved. 
still experienced a GCA flare during the study period. Treatment with MTX plus TCZ in patients with rheumatoid arthritis has been shown to be more effective than either drug in isolation ${ }^{21}$. It is unknown whether similar findings will be seen in patients with GCA, particularly those with relapsing disease. The GiACTA protocol allowed for patients taking MTX for $>6$ weeks to continue on a stable dose during the study period, although only $17 \%$ of trial subjects were taking MTX $^{22}$. Further subgroup analysis determining the potential role of adjunct MTX in patients with GCA receiving TCZ treatment is needed.

This study must be evaluated in the context of its limitations. First, and most importantly, the retrospective design limits abstracted data to information available in the medical record. Second, initiation and titration of MTX was not standardized and was at the discretion of the treating provider. The lack of standardization regarding which patients were chosen for MTX treatment affects the generalizability of these findings. Aside from higher relapsing rates prior to initiation of MTX, we did not observe a higher frequency of measured comorbidities or disease characteristics in patients treated with MTX. It is possible that unmeasured factors could have influenced the physician determination of MTX initiation, for which we could not control. However, given the lack of widely accepted consensus guidelines on the treatment of relapsing GCA, initiation of MTX based on provider preference in this cohort simulates real-world experience of GCA management. Third, patients in the MTX group had a higher starting dose of prednisone at MTX initiation/index date. While this was statistically significant, we do not consider the 4-mg higher dose at initiation and the average $2-3 \mathrm{mg}$ /day higher dose annually to be responsible for the clinically significant relapse rate reduction. This is supported by the attenuated but still significant findings despite accounting for starting dose and GC use during followup. Fourth, the lack of standardized GC tapering prevents comprehensive analysis of GC-sparing effects. Because patients started on MTX had higher frequency of relapse prior to MTX initiation, it is possible that physician and/or patient preference regarding continuation of prednisone at low doses or with slower tapers may have contributed to ongoing use of GC, rather than tapering to discontinuation resulting in similar rates of achieving prednisone doses of $<10 \mathrm{mg} /$ day for $>6$ months and prednisone discontinuation $>6$ months between cases and controls. Admittedly, we are not able to completely exclude the effect of chronic low-dose GC and their role in lowering relapse rates in this group; nevertheless, adjustment for GC use during followup after MTX initiation did not change the significance of the relapse rate reduction.

Our study has several strengths including its case-control design and longterm followup. In addition, compared to prior clinical studies, higher initial and maximal doses of MTX were used, reflecting real-world experiences with this medication. Further, to our knowledge this study comprises the largest North American cohort of relapsing patients with GCA treated with MTX described to date.

MTX is well tolerated in longterm use among patients with GCA. In addition, MTX can be considered as an adjunct medication in patients with a high frequency of flares and demonstrates benefit in reducing the rate of relapse. The utility of MTX plus TCZ in GCA is unknown, but information identifying the efficacy of this combination is anticipated.

\section{REFERENCES}

1. Lawrence RC, Helmick CG, Arnett FC, Deyo RA, Felson DT, Giannini EH, et al. Estimates of the prevalence of arthritis and selected musculoskeletal disorders in the United States. Arthritis Rheum 1998;41:778-99.

2. Gonzalez-Gay MA, Garcia-Porrua C, Llorca J, Hajeer AH, Branas $\mathrm{F}$, Dababneh A, et al. Visual manifestations of giant cell arteritis. Trends and clinical spectrum in 161 patients. Medicine 2000;79:283-92.

3. Nuenninghoff DM, Hunder GG, Christianson TJ, McClelland RL, Matteson EL. Incidence and predictors of large-artery complication (aortic aneurysm, aortic dissection, and/or large-artery stenosis) in patients with giant cell arteritis: a population-based study over 50 years. Arthritis Rheum 2003;48:3522-31.

4. Mukhtyar C, Guillevin L, Cid MC, Dasgupta B, de Groot K, Gross $\mathrm{W}$, et al. EULAR recommendations for the management of large vessel vasculitis. Ann Rheum Dis 2009;68:318-23.

5. Dasgupta B, Borg FA, Hassan N, Alexander L, Barraclough K, Bourke B, et al. BSR and BHPR guidelines for the management of giant cell arteritis. Rheumatology 2010;49:1594-7.

6. Martinez-Lado L, Calvino-Diaz C, Pineiro A, Dierssen T, Vazquez-Rodriguez TR, Miranda-Filloy JA, et al. Relapses and recurrences in giant cell arteritis: a population-based study of patients with biopsy-proven disease from northwestern Spain. Medicine 2011;90:186-93.

7. Labarca C, Koster MJ, Crowson CS, Makol A, Ytterberg SR, Matteson EL, et al. Predictors of relapse and treatment outcomes in biopsy-proven giant cell arteritis: a retrospective cohort study. Rheumatology 2016;55:347-56.

8. Alba MA, Garcia-Martinez A, Prieto-Gonzalez S, Tavera-Bahillo I, Corbera-Bellalta M, Planas-Rigol E, et al. Relapses in patients with giant cell arteritis: prevalence, characteristics, and associated clinical findings in a longitudinally followed cohort of 106 patients Medicine 2014;93:194-201.

9. Proven A, Gabriel SE, Orces C, O'Fallon WM, Hunder GG. Glucocorticoid therapy in giant cell arteritis: duration and adverse outcomes. Arthritis Rheum 2003;49:703-8.

10. Stone JH, Tuckwell K, Dimonaco S, Klearman M, Aringer M, Blockmans D, et al. Trial of tocilizumab in giant-cell arteritis. N Engl J Med 2017;377:317-28.

11. Spiera RF, Mitnick HJ, Kupersmith M, Richmond M, Spiera H, Peterson MG, et al. A prospective, double-blind, randomized, placebo controlled trial of methotrexate in the treatment of giant cell arteritis (GCA). Clin Exp Rheumatol 2001;19:495-501.

12. Hoffman GS, Cid MC, Hellmann DB, Guillevin L, Stone JH, Schousboe J, et al. A multicenter, randomized, double-blind, placebo-controlled trial of adjuvant methotrexate treatment for giant cell arteritis. Arthritis Rheum 2002;46:1309-18.

13. Jover JA, Hernandez-Garcia C, Morado IC, Vargas E, Banares A, Fernandez-Gutierrez B. Combined treatment of giant-cell arteritis with methotrexate and prednisone. A randomized, double-blind, placebo-controlled trial. Ann Intern Med 2001;134:106-14. 
14. Mahr AD, Jover JA, Spiera RF, Hernandez-Garcia C, Fernandez-Gutierrez B, Lavalley MP, et al. Adjunctive methotrexate for treatment of giant cell arteritis: an individual patient data meta-analysis. Arthritis Rheum 2007;56:2789-97.

15. Leon L, Rodriguez-Rodriguez L, Freites D, Arietti L, Morado I, Vadillo C, et al. Long-term continuation of methotrexate therapy in giant cell arteritis patients in clinical practice. Clin Exp Rheumatol 2017;35 Suppl 103:165-70.

16. Leon L, Rodriguez-Rodriguez L, Morado I, Rosales Z, Vadillo C, Freites D, et al. Treatment with methotrexate and risk of relapses in patients with giant cell arteritis in clinical practice. Clin Exp Rheumatol 2018;36 Suppl 111:121-8.

17. Muratore F, Kermani TA, Crowson CS, Green AB, Salvarani C, Matteson EL, et al. Large-vessel giant cell arteritis: a cohort study. Rheumatology 2015;54:463-70.

18. Krall PL, Mazanec DJ, Wilke WS. Methotrexate for corticosteroid-resistant polymyalgia rheumatica and giant cell arteritis. Cleve Clin J Med 1989;56:253-7.
19. Camellino D, Morbelli S, Sambuceti G, Cimmino MA Methotrexate treatment of polymyalgia rheumatica/giant cell arteritis-associated large vessel vasculitis. Clin Exp Rheumatol 2010;28:288-9

20. Hernandez-Garcia C, Soriano C, Morado C, Ramos P, Fernandez-Gutierrez B, Herrero M, et al. Methotrexate treatment in the management of giant cell arteritis. Scand J Rheumatol 1994;23:295-8.

21. Kaneko Y, Atsumi T, Tanaka Y, Inoo M, Kobayashi-Haraoka H, Amano K, et al. Comparison of adding tocilizumab to methotrexate with switching to tocilizumab in patients with rheumatoid arthritis with inadequate response to methotrexate: 52-week results from a prospective, randomised, controlled study (SURPRISE study). Ann Rheum Dis 2016;75:1917-23.

22. Unizony SH, Dasgupta B, Fisheleva E, Rowell L, Schett G, Spiera $\mathrm{R}$, et al. Design of the tocilizumab in giant cell arteritis trial. Int $\mathrm{J}$ Rheumatol 2013;2013:912562.

APPENDIX 1. Mean annual prednisone dose reduction following methotrexate initiation (cases) or index date (controls).

\begin{tabular}{lccc}
\hline Year & Cases & Controls & $\mathrm{p}$ \\
\hline Index to 1 yr & $-14.4( \pm 15.3) \mathrm{mg} /$ day & $-12.8( \pm 20.9) \mathrm{mg} / \mathrm{day}$ & 0.31 \\
1 yr to 2 yrs after index & $-3.0( \pm 5.0) \mathrm{mg} /$ day & $-4.1( \pm 9.8) \mathrm{mg} / \mathrm{day}$ & 0.31 \\
2 yrs to 3 yrs after index & $-1.6( \pm 3.3) \mathrm{mg} /$ day & $-2.1( \pm 7.1) \mathrm{mg} / \mathrm{day}$ & 0.49 \\
3 yrs to 4 yrs after index & $-1.1( \pm 2.7) \mathrm{mg} /$ day & $-0.5( \pm 1.9) \mathrm{mg} /$ day & 0.85 \\
4 yrs to 5 yrs after index & $0.0( \pm 2.2) \mathrm{mg} /$ day & $0.7( \pm 8.9) \mathrm{mg} /$ day & 0.66 \\
\hline
\end{tabular}

